\title{
LA INFLUENCIA DE LA RELIGIÓN EN LA COMPOSICIÓN DEL PAISAJE URBANO HISPANOAMERICANO
}

\author{
Rosselvelt José Santos \\ Universidade Federal de Uberlândia, Instituto de Geografia, Uberlândia, MG, Brasil \\ rosselvelt@ufu.br \\ Gina Lobato Cordero \\ Universidade Federal de Uberlândia, Instituto de Geografia, Uberlândia, MG, Brasil \\ ginasoloco@hotmail.com
}

\begin{abstract}
RESUMEN
La imposición de la religión católica en territorio americano durante la conquista europea, como una de las estrategias de dominio, no solamente modifico el sistema de creencias indígenas del continente, sino también influenció en la composición del paisaje, principalmente urbano, debido a la representación de su cosmovisión en éste. Así, este trabajo analiza como el paisaje cultural hispano-americano fue capturado por la religión católica, y por imposición fue materializado. Posteriormente, estas imposiciones continuarán presentes en el proceso de mestizaje cultural. De esta manera, las tradiciones indígenas fueron catalogadas como prácticas carentes de conocimiento, banalizando los elementos que constituyen sus deidades. Con todo, algunas reminiscencias autóctonas continúan siendo empleadas como un bien patrimonial que nutre y reproduce el capital invertido en las ciudades, sobre todo para fines turísticos. Se trabajó con una lectura de los elementos representativos en dos áreas declaradas patrimonio cultural de la humanidad, y que son representativas de las culturas Inca en América del Sur y Azteca en Mesoamérica.
\end{abstract}

Palabras clave: Dioses. Vegetación. Culto. Cultura. Indígena.

\section{A INFLUÊNCIA DA RELIGIÃO NA COMPOSIÇÃO DA PAISAGEM URBANA HISPANOAMERICANA}

\begin{abstract}
RESUMO
A imposição da religião católica em território americano durante a conquista européia, como uma das estratégias de domínio, não somente modificou o sistema de crenças indígenas do continente, mas também influenciou a composição da paisagem, principalmente urbana pela representação de sua cosmología. Este trabalho analisa como a paisagem cultural hispano-americana foi capturada pela religião católica e por imposição, foi materializando-a. Posteriormente, essas imposições continuaram presentes no processo de mestiçagem cultural. Assim, as tradições indígenas foram classificadas como práticas carentes de conhecimentos descaracterizando os elementos que constituem suas identidades. Contudo, as reminiscências autóctones continuam sendo usadas como um bem patrimonial que nutre e reproduzir os capitais investidos nas cidades, sobretudo, para fins turísticos. Uma leitura dos elementos representativos foi feita em duas áreas declaradas como patrimônio cultural da humanidade, e que são representativas das culturas Inca na América do Sul e Azteca em Messo América.
\end{abstract}

Palavras-chave: Deuses. Vegetação. Culto. Cultura. Indígena.

\section{INTRODUCCIÓN}

El objetivo de este trabajo, es mostrar como la influencia religiosa tiene un alcance urbano paisajista que modifica y condiciona la patrimonialidad de la cultura. Hecho que en Latino América e Hispano América principalmente, se aprecia en algunos de los centros religiosos católicos, de anterior y diferente religiosidad, que hoy por hoy se encuentran bajo el dominio de intereses turísticos que no dialogan con la salvaguarda cultural de estos.

$\begin{array}{llllll}\text { Caminhos de Geografia } & \text { Uberlândia - MG } & \text { v. 19, n. } 68 & \text { Dez/2018 } & \text { p. 296-306 } & \text { Página } 296\end{array}$


Es así que el denominado mestizaje ocurrido en América, es evidentemente el marco que permite el encuentro de dos culturas originariamente diferentes, que en un momento específico convivieron en un espacio determinado, dando inició a un proceso de mestizaje, del que resultarán los pueblos latinoamericanos y sus ciudades, muchas de ellas patrimonio cultural de la humanidad, en la actualidad. Este mencionado proceso tiene sus principales representantes en Hispano América, por el norte estuvieron los Aztecas o Mexicas, en México; en Centro América y parte de México los Mayas; y en Sud América los Incas. Estos pueblos originarios se encontraban a la cabeza, dominando sus territorios bajo sus propias formas de vida y cosmovisión, la que de alguna manera presentaba similitudes en todo el mencionado territorio. Por otro lado, estuvieron los conquistadores españoles, quienes a su vez contaban también con su propia cosmovisión, que para el caso estará representada por la Iglesia Católica, desembarcando en tierras americanas en el siglo XVI, conjuntamente con la llamada conquista española.

Durante su convivencia, estrategias de domino fueron empleadas por los conquistares, quienes con la bendición de la Iglesia y por órdenes de la Corona española, llevaron a cabo una avasallante imposición religiosa a fin de conseguir sus objetivos. La forma de imposición puede percibirse en la condenación de la religiosidad y todas las prácticas nativas, la suplantación de estas y la materialización de una religión que establece sus bases en el catolicismo. Sin embargo, a pesar del tiempo transcurrido y los daños superados, Hispanoamérica adopto la nueva religión impuesta enriqueciéndola con elementos originarios que se adecuaron para conseguir dar sentido y continuidad a las prácticas tradicionales. Así como la conformación de sus ciudades que se convirtieron en reproducciones europeas acopladas a un contexto climático y cultural desemejante al europeo. Como Hardoy (1972) apunta que las ciudades coloniales hispanoamericanas son un modelo importado, que gradualmente se adaptó a las necesidades del proceso fundacional.

Siendo en éste construir, que muchos elementos naturales y de composición paisajística, debieron ser suplantados y ocultados para conseguir el dominio y la veneración de los conquistados. Ya que le sentido de la vegetación, en culturas prehispánicas, cumplió un papel primordial en la conformación de su territorio. Pero que, a pesar de los acontecimientos ocurridos, ésta resistió a las imposiciones socioculturales, ajustándose de alguna manera a las nuevas formas de vida en el paisaje indoamericano. De esta manera es posible hablar de una enraizada herencia cultural indígena en el paisaje, pero difícilmente de un reconocimiento del sentido cultural patrimonial mestizo en éste, debido al complicado proceso de mestizaje, en el que la religión católica ejerció una estrategia de dominio que condenó la relación hombre-naturaleza, de la que no se consigue superar a pesar de hacer sido adjudicada en el siglo XVI en América, "Mientras no logremos corregir los conceptos, no será posible que obremos sobre el medio físico en tal forma que lo hagamos servir a nuestro propósito" (VASCONCELOS, 2005, p.12).

\section{METODOLOGÍA}

Se procuran dos áreas declaradas patrimonio cultural de la humanidad, ubicadas en la zona andina y mesoaméricana de Hispanoamérica. Que compartan semejanzas en la composición paisajista; que formen parte del entorno urbano de la ciudad prehispánica; que tengan un centro religioso o edificación ceremonial prehispánico sobre la cual se haya construido una iglesia o semejante por parte de la iglesia católica; y que actualmente dediquen o se alineen con actividades turísticas en función de su herencia patrimonial. Para este análisis se consideran, el área de Pumapungo en Cuenca Ecuador como representante paisajístico del mestizaje cultural entre incas y españoles en la zona andina; y Xochimilco, el área del convento y la iglesia de San Bernardino de Siena, como muestra del paisaje mestizo entre aztecas y españoles en la zona mesoaméricana. Estas dos áreas patrimoniales fueron además centros importantes de cultivo, lo que permite mostrar la importancia del sentido de los elementos vegetales y naturales en general, que encuentran en el paisaje un lienzo en donde materializarse. Para así, por medio de fuentes escritas, identificar elementos rituales-vegetales que puedan dar cuenta de la influencia del dogma católico en el paisaje hispanoamericano. Áreas urbanas, que con el tiempo se alinearon a un sistema turístico mercantilista que especula el valor del espacio urbano patrimonializado.

\section{EL SENTIDO DE LA VEGETACIÓN Y EL PAISAJE EN EL ENTORNO URBANO PREHISPÁNICO}

La utilización de la vegetación en la vida urbana de las ciudades prehispánicas, parece responder a dos factores de gran alcance, el ritual y el alimenticio. No obstante, éste último no carece de

$\begin{array}{llllll}\text { Caminhos de Geografia } & \text { Uberlândia - MG } & \text { v. 19, n. } 68 & \text { Dez/2018 } & \text { p. 296-306 } & \text { Página } 297\end{array}$


ritualidad, aunque posee una diferencia por jerarquías entre sus propietarios o cultivadores. Espacios de cultivo que, en base a las descripciones históricas mantenían una relación ritual con sus usuarios, que no tenían nada que ver con los cánones europeos de los conquistadores a su llegada al nuevo continente. Lo que de alguna manera el hablar de urbanidad, ciudad, y paisaje, estos conceptos les fueron atribuidos a su llegada, como aparente exclusividad europea y de indirecto dominio de la iglesia. Esto no significaba que no existían dichas formas de organización en el Tahuantinsuyo, al contrario, éste contada con una organización urbana armónicamente construida con el paisaje, que a su vez respondía a un dialogo estrecho con su cosmovisión.

El cristianismo venido desde Europa, con su centro religioso en Roma, se consolidó sobre precedentes construcciones de naturaleza mágica de los pueblos anteriores, como el caso de etruscos, griegos y campanios. Sin embargo, de estos pueblos no se salvaguardan referencias para con el cristianismo, de igual manera fueron desmerecidos ante el poder de la iglesia católica. Por lo que esta práctica de sometimiento, no fue nada nueva al momento de aplicarla en América. De esta manera, el territorio Incaico en la región andina, y el territorio Mexica en el valle de México, fueron considerados como nuevos puntos de interés para diseminar, por imposición, la religión católica.

\begin{abstract}
"A pesar de la presencia general de prácticas "idólatras" autóctonas tan desesperadamente combatidas por las autoridades católicas, se creía que el potencial didáctico de las imágenes religiosas para la cristianización era tan importante que se aceptó la posibilidad de su veneración no autorizada por los nativos. Sin embargo, el texto de 1567 menciona la relación ambigua entre la imagen material y el sujeto representado, lo que constituyó un serio problema para la Iglesia Católica desde los primeros tiempos del cristianismo. Mientras que la doctrina católica consideraba las imágenes religiosas como referencias a las ideas que representaban, los españoles vieron a los "ídolos" nativos (huacas) como objetos venerados. Mientras que la veneración católica de una imagen se refería al santo representado "a través del acto de recordar" (Baumgarten 37), la veneración del "ídolo" estaba dirigida, a los ojos de los españoles, al objeto mismo." (WINDUS, 2011, p. 96) ${ }^{1}$
\end{abstract}

Es así que los lugares y los elementos de culto prehispánico a ser intervenidos con el objetivo de evangelizar, son los encontrados en el entorno natural, como vegetación, animales, cerros. Así como en la conformación urbana de las ciudades en donde se encontraban construcciones específicas que cumplían la función de albergar a las más importantes deidades, como el Templo del sol, de la Luna, así como también las representaciones urbanas con formas de animales como el cóndor, el puma, pueden ser identificadas en el incario. En la zona de central de México, centro de control de los mexicas, puede encontrarse principalmente pirámides y teocalis dedicados a las deidades del Sol, de la Luna, Tláloc, dios de la lluvia, Quetzalcóatl, llamada serpiente emplumada, de entre los más poderosos. Las formas de cultivo en el conocido sistema lacustre, en el que se emplean las chinampas, en el área de Xochimilco, demuestran el dominio y el conocimiento con el que estos territorios prehispánicos fueron planificados y construidos. Quizás una ventaja de los mexicas, es que, al contar con una escritura, se puede tener un mejor alcance, aparente, a la información que da cuenta de su forma de vida y cosmovisión. De todas maneras, ambas culturas mantienen un dialogo estrecho y profundo con su entorno natural, del que se alimentan y al que le rinden tributo en su territorio.

El caso del maíz es quizás el más representativo. Éste estaba relacionado con Inti, el incaico dios Sol, era la base de la alimentación andina, además de ser empleado en variadas preparaciones como la chicha, bebida que se obtiene del fermento del maíz, y que a su vez es consumida de forma ritual o como energético durante el cumplimiento de arduas tareas. La idea de vastas plantaciones, resulta

\footnotetext{
${ }^{1}$ Despite the overall presence of indigenous 'idolatrous' practices so desperately combated by Catholic authorities, the didactic potential of religious images for Christianization was believed to be of such importance that the possibility of their unsanctioned veneration by the natives was accepted. Nevertheless, the text from 1567 mentions the ambiguous relationship between the material image and the represented subject, which constituted a serious problem für the Catholic Church since early Christian times. Whereas Catholic doctrine regarded religious images as references to the ideas they represented, the Spaniards saw the native 'idols' (huacas) as venerated objects. Whereas the Catholic veneration of an image referred to the represented saint "through the act of remembering" (Baumgarten 37), the veneration of the 'idol' was directed, in the eyes of the Spaniards, to the object itself.

$\begin{array}{llllll}\text { Caminhos de Geografia } & \text { Uberlândia - MG } & \text { v. 19, n. 68 } & \text { Dez/2018 } & \text { p. 296-306 Página } 298\end{array}$
}


evidente ya que el Señorío de los Incas albergo gran parte del territorio andino y los pueblos en éste asentados. No obstante, la magnitud de cultivos no se deslinda de la ritualidad, pero efectivamente es de mayor evidencia en áreas de acceso exclusivo del Inca y las elites, como el caso de los espacios verdes contiguos al Coricancha o Templo del Sol. Así el nombrado jardín del Coricancha de Tomebamba en Cuenca Ecuador, "El jardín contiguo mostraba un vergel de: plantas, árboles, animales, insectos, caracolas, de tamaño natural vaciados en oro y plata" (BANCO CENTRAL, 1997, p.27). En el cual se encontraban sembrados maizales, "estaba artificiosamente sembrado de maizales, los cuales eran [de] oro, así las cañas de ellos como las hojas y mazorcas, y estaban tan bien plantados que, aunque hiciese recios vientos, no se arrancaban" (CIEZA DE LEÓN, 2005, p. 361 ), ver figura 1, y entre éstos se colocadan representaciones de la planta de maíz, labradas en oro, metal que también estaba relacionado con el dios Sol, cumpliendo con una función ritual durante solsticios principalmente.

Figura 1: Vegetación cultivada en Pumapungo, Cuenca de los Andes; y en las Chinampas, Xochimilco, Ciudad de México

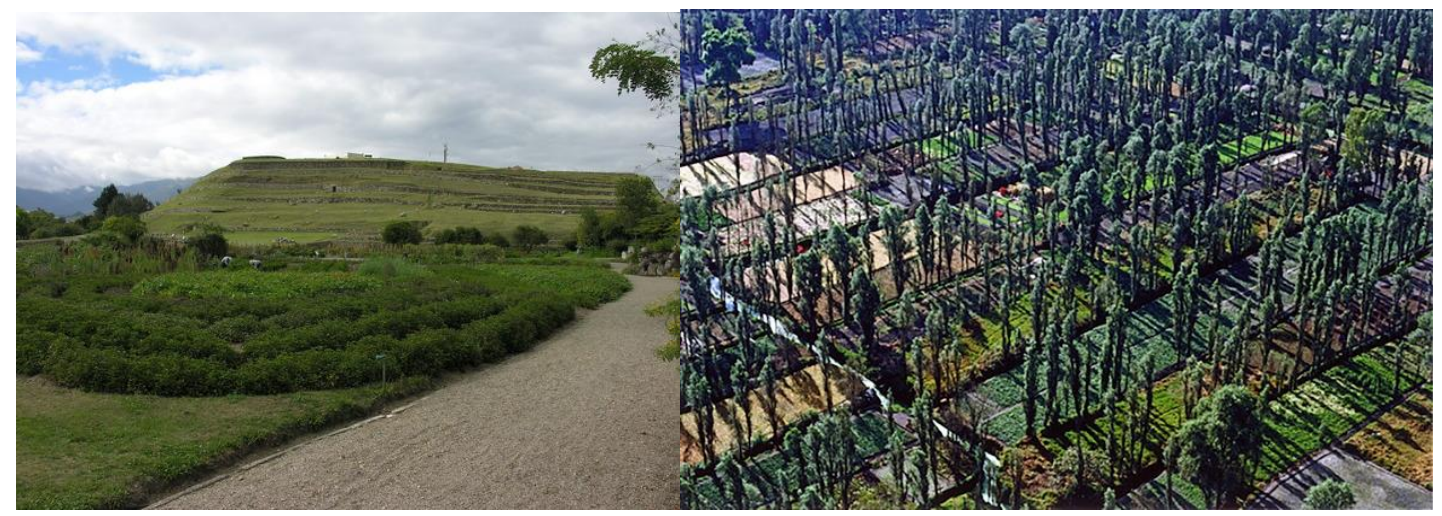

Fuente: el autor, 2014; INAH Mediateca, 2017.

Por su parte al norte de Ciudad de México, Xochimilco es un área considerada como de "producción agrícola", en la que se cultivaba gran parte del alimento para el pueblo mexica. Las características lacustres del suelo de cultivo, exigían un tipo de vegetación adecuado, "Se producía maíz, frijol de diversos tipos, chiles, calabazas, chayotes, amaranto, chía, varios frutales y flores, seguramente muchas flores, pues Xochimilco significa 'En la sementera de flores'” (STEPHAN-OTTO, 1998, p. 10), por lo que el maíz, el frejol, la calabaza y algunas flores entre las mas conocidas, cumplían con este requerimiento. No obstante, ésta vegeteación además de ser empleada para la alimentación, era también utilizada en rituales, como el caso del maíz, "El ciclo de crecimiento de la planta de maíz había sido un elemento decisivo en el ceremonial indígena de antes de la conquista, y siguió rigiendo la vida daría de los indios" (GIBSON, 1977, p. 313).

En Xochimilco, se han encontrado teocalis de los que aún no se han especificado a que deidad podrían estar dedicados. Sin embargo, por la composición paisajística en la que el agua y las flores son de predominio, se puede conjeturar que posiblemente eran para, Tláloc, dios de la lluvia; Xochipilli, dios de las flores; o Xochiquétzal, dios de la fertilidad, quienes podrían haber tenido su espacio de culto en esta área. Como se puede apreciar, para el caso andino son posiblemente cultivos de importancia ritual los que están junto a las edificaciones dedicadas a deidades, pero sin especificar que eran áreas exclusivamente de producción de alimento. Contrario al caso mexica, un espacio de gran belleza natural 'creado', en la que el cultivo históricamente ha sido especificado como de producción de alimento.

Las áreas en donde el cultivo no está directamente ligado a un espacio construido de culto específico, de igual manera cuentan con la presencia de formas rituales que bendigan el crecimiento y la cosecha. En el área andina, se han encontrado figuras enterradas junto a la vegetación, mismas que cumplen con la función de aproximarse a lo que se espera cosneguir al momento de la cosecha, estas representaciones en barro, metal o piedra son llamadas de Yllas, "Son objetos de 'adoración' como las huacas y eran heredadas de padres a hijos, siendo utilizadas en el rito íntimo de cada familia" (MANRÍQUEZ, 1999, p. 109).

$\begin{array}{llllll}\text { Caminhos de Geografia } & \text { Uberlândia - MG } & \text { v. 19, n. } 68 & \text { Dez/2018 } & \text { p. 296-306 } & \text { Página } 299\end{array}$


Semejantes ritualidades tienen las figuras encontradas en áreas de cultivo mexica, con la especificidad que representa al dios de la fertilidad, así también como una forma de conseguir su bendición al ser enterradas, de igual manera, junto a la vegetación. "Como diosa de la fecundidad, la imagen de Xochiquétzal aparece en infinidad de figurillas por los campos de México, ya que 'era costumbre enterrar esas figuras antes de la siembra a fin de que la diosa se encargara de hacer germinar el grano"' (ALCINA, 1991, p. 77).

Por otro lado, las visuales desde estos lugares, incarico y mexica, tienen una ubicación desde la cual, el paisaje circundante muestra las deidades de formación natural como el caso de cerros, volcanes y elevaciones con una gran influencia ritual. Desde el Coricancha de Cuenca, la llamada geografía sagrada puede ser identificada, en los puntos a los que se dirigen las líneas de ceques, puntos que son representados por elevaciones como el Cojitambo, Pacha Mama, Guagual Shumi, Turi, Boquerón. Desde Xochimilco tomando como referencia el teocali sobre el cual se construyera el templo de San Bernardino, se encuentran el volcán Teuhtili Xochimilco, el cerro Tlacualleli, el volcán Zompole, ver figura 2.

Figura 2: Mapas de la geografía sagrada vista desde el Coricancha en Cuenca de los Andes; y desde la Iglesia de San Bernardino de Siena en Xochimilco, Ciudad de México.

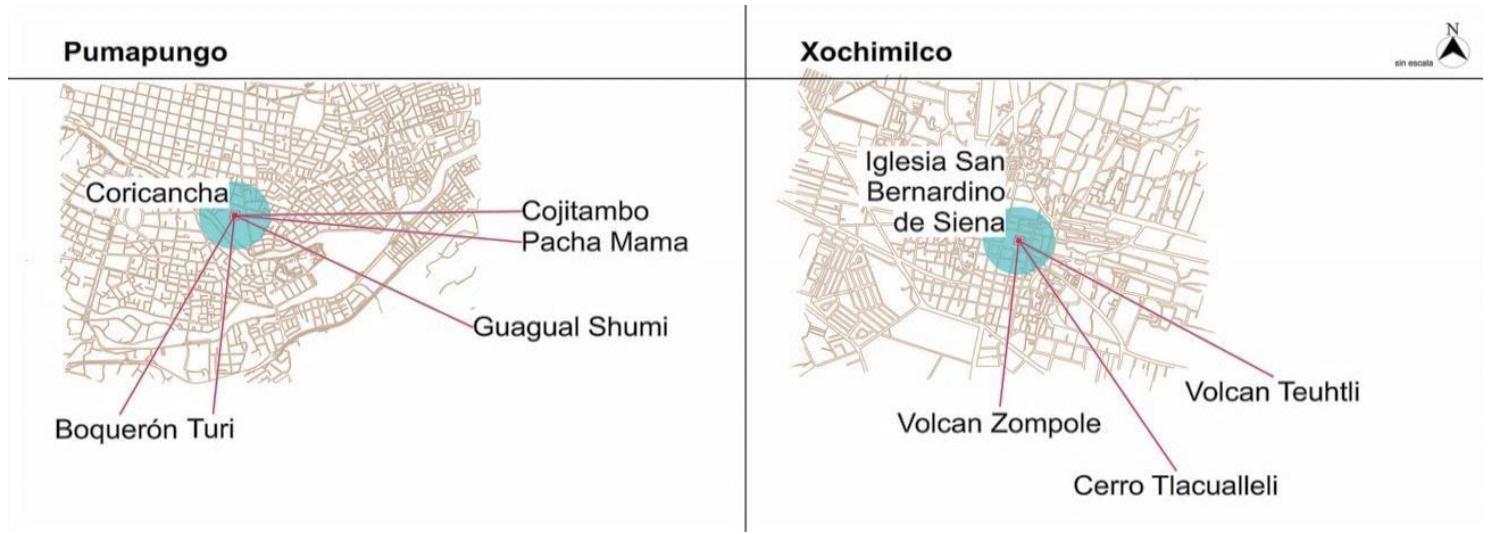

Fuente: el autor, 2017.

\section{EL DIÁlOgo de los RITUALES PREHISPÁNICOS CON LA ESTRATEGIA DESMITIFICADORA DE LA IGLESIA CATÓLICA SOBRE LOS LUGARES DE CULTO PREHISPÁNICOS}

Con la llegada del cristianismo a América, el sentido de los rituales y su continuidad, de acuerdo al paisaje y los elementos naturales expresados desde la cosmovisión prehispánica, no encuentran un equilibrio de convivencia. Por lo que, de cualquier forma, la religió católica deberá ser impuesta, con las mismas estrategias, o quizás más violentas, a las empleadas en territorio europeo. Es así que la erradicación o sustitución de deidades, es primordial. Al ser éstas elementos naturales, se podría pensar que la tarea fue ardua, ya que el sol, las montañas, la luna, el agua y demás, no se pueden cubrir. "El maíz y el frijol dejarán de ser cultivos básicos, para poco a poco ser reemplazados por las hortalizas europeas que traen los españoles, y que hasta entonces eran desconocidas en Mesoamérica" (CANO VALLADO, 1999, p. 218). De esta forma, también la vegetación en sus usos tanto alimenticios como rituales, se verá fuertemente suplantada por la vegetación introducida paulatinamente al continente americano, aun con las dificultades naturales de un clima, tierra, y condiciones geográficas completamente diversas a las del viejo continente.

También en el incario sucederá esta suplantación de cultivos, a los que además ya se les identificaba con importancia ritual, siendo imperante controlar estas prácticas. "A este tono cualquier cosa que tenga extrañeza entre los de su género, les parecía que tenía divinidad, hasta hacen esto con pedrezuelas y metales, y aún raíces y frutas de la tierra, como en raíces que llaman papas, hay y unas extrañas a quienes ellos les ponen el nombre de 'llalahuas' y los besan y los adoran" (PADRE JOSÉ ACOSTA, 1954, p.145 apud ESTRELLA, 1988, p.129). Igualmente, en donde se ubicaban los templos de culto solar como el Coricancha en Cuzco y en Tomebamba, pasaron a ser de dominio de la iglesia, construyendo sobre éstos, principalmente, o en algunos casos junto a éstos, las

\begin{tabular}{llllll}
\hline Caminhos de Geografia & Uberlândia - MG & v. 19, n. 68 & Dez/2018 & p. 296-306 & Página 300
\end{tabular}


edificaciones para albergar a una comunidad religiosa cristiana católica, así como un templo o capilla para celebrar sus rituales religiosos. En territorio mexica, la iglesia de San Bernardino de Siena, cubrió completamente un teocalli del que estudios actuales, dan cuenta de su existencia. Como se indicó anteriormente, la deidad a la que este estaba dedicado no se establecido, pero sí su importante conexión con la geografía sagrada que le rodea y los elementos del paisaje, ver figura 3.

Figura 3: Coricancha en Cuenca-Ecuador; Teocali en Xochimilco-México.

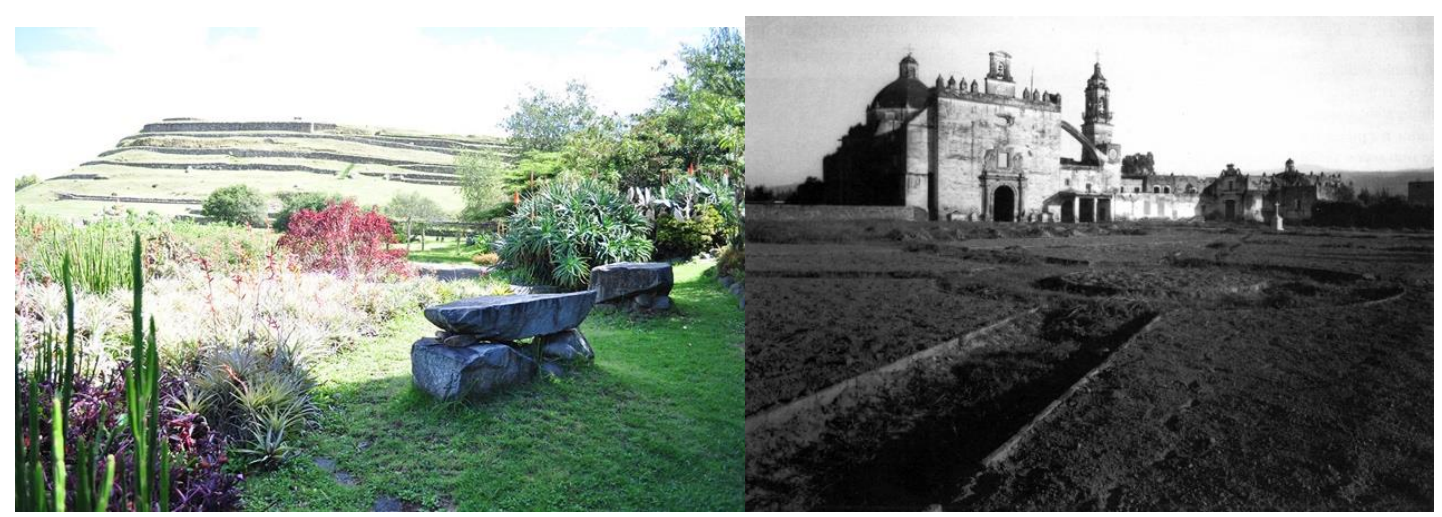

Fuente: el autor, 2014; INAH Mediateca, 2017.

Esta práctica impositiva fue antes aplicada en la misma Europa. No obstante, cabe anotar que las diferencias climáticas son un factor de gran influencia en el diseño y construcción de estos centros urbanos, debido a que, el invierno y el verano no tienen la misma intensidad en las áreas andinas y mesoamericanas que en Europa. De esta manera, las bondades del clima americano permitirían un culto en el que la espacialidad construida establecía un dialogo armónico con el paisaje. Contrario al culto católico, que propone confinar a sus fieles al interior de edificaciones propositivamente construidas, aislando su relación con el paisaje natural alrededor, definiendo así los límites del dominio del hombre en la tierra, en donde los fieles son adoctrinados y el ritual puede ser mejor controlado.

Sin embargo, investigaciones en territorio andino y mesoamericano han propuesto la posibilidad de 'capillas abiertas'. "La investigación ha estado centrada, durante muchos años, en las tierras del virreinato de la Nueva España, pero las aportaciones más recientes han demostrado la existencia de estas sencillas estructuras en territorio del virreinato peruano." (MORALES, 1983, p. 453-454). Éstas consistían en cubrir solamente la zona desde la cual el sacerdote imparte el culto, dejando al público a espacio abierto, sin ningún tipo de resguardo, "en tierras americanas, en donde se partía de estructuras provisionales, tales como púlpitos destinados a la predicación, para pasar más tarde, a la construcción de estructuras estables, tipo balcones o capillas, en los que celebrar los cultos o pronunciar sermones." (MORALES, 1983, p. 461). Práctica que es aplicada en pocos lugares en Hispano América, y que al parecer según Gisbert y De Mesa (1985, p. 130), fue una concesión de los españoles para con los indígenas. Indulgencia que concedía de alguna manera, una evangelización más congruente con la arraigada cosmovisión prehispánica, habiendo flexibilizado con este hecho ciertas prácticas cristianas para lograr su objetivo. Ésto reafirmaría el lazo hombre-naturaleza en ambos territorios americanos, en contraste con la poca relación entre, espacio sagrado y naturaleza que predica el catolicismo. En consecuencia, el espacio urbano atiende estas demandas, dando paso a una convivencia cultural y religiosa.

"La voluntad de suprimir físicamente o cuanto menos de desactivar los usos sacramentales del espacio público, fueran edificaciones, monumentos, elementos de la decoración doméstica u ocupaciones protocolizadas en forma de desplazamientos o concentraciones, culminaba un proceso que arranco en el siglo XVI y que todavía está por completarse en muchas naciones, sobre todo en América Latina, en las que la religiosidad popular de denominación católica continua obstruyendo no sólo los intentos de reforma encarnados por las corrientes protestantes, sino también a los 
esfuerzos de la propia Iglesia católica por redimir una exterioridad ritual de la que su teología abomina." (DELGADO RUIZ, 1997, p. 175).

Si bien en Europa a partir del siglo XV la iglesia no debía tener presencia en el espacio público, condicionando su papel en el proceso de territorialización de las creencias. En el caso de Hispanoamérica, parecería que esta condición se deberá reajustar a la necesidad de autoridad, de tal manera que, si la religiosidad de las cosmovisiones prehispánicas forma parte del espacio público dentro de la identidad territorial, al suplantarlas por el catolicismo, deberían adoptar esta condición tornando aun más complicada, pero a su vez otorgandole mayor poder, a la presencia de la iglesia en el imaginario colectivo de los colonizados y los colonizadores. Debido a que el colonizado era conocedor de las bendiciones y castigos de sus deidades, las que al ser suplantadas arrastrarán consigo estas condiciones; lo que en el caso de los colonizadores el desconocimiento y la idea demoniaca concedida a estas prácticas culturales, tornaría a su vez vulnerable su religiosidad de no ser impartida despiadadamente.

\begin{abstract}
"En contraste, no había una separación estricta entre la esfera sacra y la terrestre en la cosmología andina, un hecho que era de crucial importancia para los sistemas de representación indígenas. Las imágenes devocionales como las huacas eran parte de la sacralización de la naturaleza; ellos reflejaron lo cosmológico y lo social como el orden social [...] las imágenes apoyan el culto, así como las piedras, las montañas y los fenómenos meteorológicos, todos los cuales tenían la misma función en la religiosidad andina. La imagen emite una invitación para ver, y ver es reconocer. Por lo tanto, la imagen inspira la visión de lo que alguien ya sabe (de Véricourt 49). Y este conocimiento difiere mucho entre y dentro de los grupos de españoles e indios." (WINDUS, 2011, p. 108-109) ${ }^{2}$
\end{abstract}

Por lo tanto, este dialogo de religiosidades es dependiente para su existencia, desde el momento en el que éstos se ven enfrentados a convivir en un mismo espacio. Lo que a su vez es abarcado por un proceso sistémico de control y dominio territorial, que representa el eje de mayor alcance sobre las culturas prehispánicas, seguido por la barbarie. La que fue empleada para controlar e imponer el dogma católico en el que las prácticas prehispánicas eran consideradas como pecados según las normas de la iglesia. "Pero las regulaciones se aplicaron no solo a los motivos, formas y contenidos de las imágenes y los objetos. También emitieron instrucciones específicas con respecto a su uso correcto por parte de los creyentes." (WINDUS, 2011, p. 108) ${ }^{3}$ Sin embargo, algunos elementos de las cosmovisiones andina y mexica, serán también incluidos en las representaciones de imágenes pintadas por españoles y mestizos para ser colocadas en los templos y lugares de culto cristiano, con el fin de impartir la doctrina, empleando también las imágenes, ver figura 4.

Por su parte, los pecados son representados por medio del cuerpo humano, en él que las acciones que éste realiza, los materializa. Si bien ciertos elementos, animales y deformaciones del cuerpo eran muy utilizados en Europa, en América no van a tener el mismo efecto. Ya que los originarios del nuevo continente veneran los materiales, vegetación, elementos naturales, animales y demás por lo que son; no están representando a alguien más, como en el caso cristiano, en el que se adora la imagen de Cristo, y no el material en el que él pueda estar representado. "Las imágenes escapan a las gramáticas de los sistemas de lenguaje en la medida en que presentan todos sus elementos simultáneamente. Esto permite que ocurran una variedad de recepciones, que corresponden y se entrelazan diferentes sistemas visuales, y se actualizan al mismo tiempo." (WINDUS, 2011, p. 111) De tal manera que, según esta cita, la intervención en el paisaje y sus elementos se convierte en una de las prácticas evangelizadoras, que facilitan, pero a su vez también complica el proceso de suplantación de una cosmovisión por el dogma católico.

\footnotetext{
${ }^{2}$ In contrast, there was no strict separation between the sacral and the earthly sphere in Andean cosmology, a fact that was of crucial importance for indigenous systems of representation. Devotional images like the huacas were part of the sacralization of nature; they refiected the cosmological as weil as the worldly and social order [...] explains, images support the cult, as well as stones, mountains, and meteorological phenomena, all of which had the same function in Andean religiosity. The image issues an invitation to see, and to see is to recognize. Therefore, the image inspires the seeing of what someone already knows (de Vedcourt 49). And this knowledge differs greatly between and within the groups of Spaniards and Indians.

${ }^{3}$ But regulations applied not only to the motifs, forms, and contents of the pictures and objects. They also issued specific instructions regarding their proper use by the believers.

${ }^{4}$ Images escape the grammars of language systems insofar as they present all their elements simultaneously. This allows a variety of receptions to occur, corresponding to and intertwining different visual systerns, and actualizing them at the same time.

$\begin{array}{llllll}\text { Caminhos de Geografia } & \text { Uberlândia - MG } & \text { v. 19, n. 68 } & \text { Dez/2018 } & \text { p. 296-306 Página } 302\end{array}$
}


Figura 4: Sud América: José López de los Ríos, 1684; Norte América: Luis de Mena, Serie de Castas, c. 1750 .

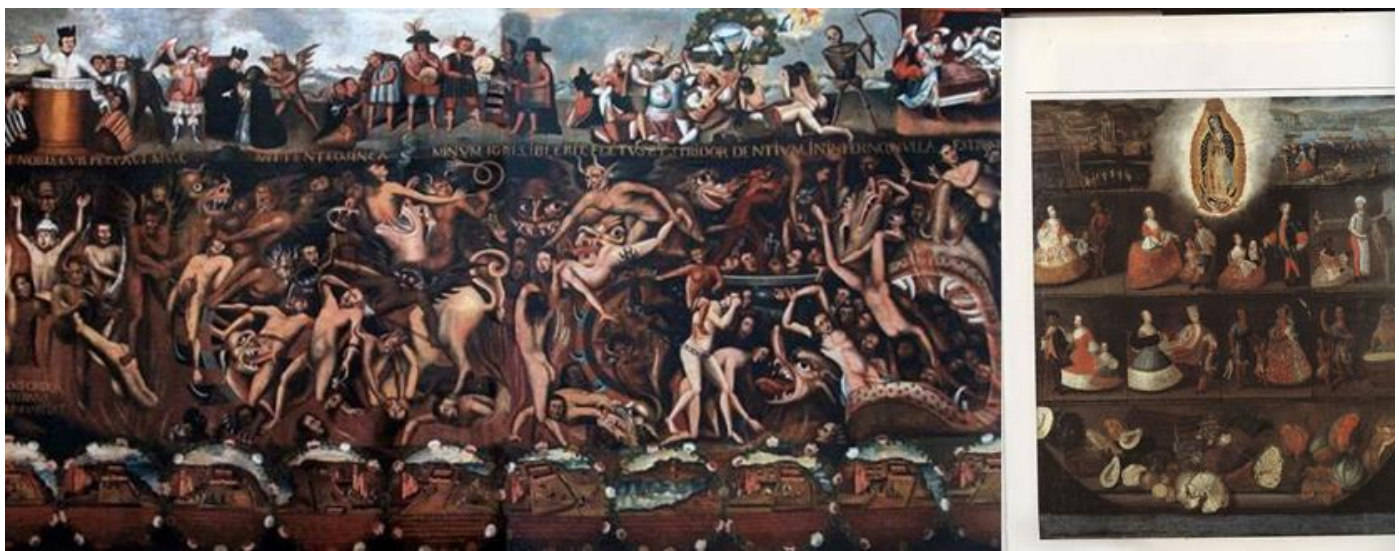

Fuente: (WINDUS, 2011, p. 108); de dominio público.

Estos procesos se verán plasmados en el patrimonio material y posteriormente en el inmaterial que se encuentra en Latinoamérica. Posiblemente las representaciones más relevantes están en territorio andino y mesoamericano. De los cuales para este trabajo fueron elegidos lugares patrimoniales mundialmente reconocidos, en los que las características paisajísticas son el componente primordial y que con el pasar del tiempo adoptaron un papel turístico dentro del espacio urbano de las ciudades en donde se encuentra. Uso que es el más difundido para éstos, pero que sin embargo se ha convertido en tema de debate en función de las amenazas al patrimonio y su patrimonialidad.

Estos son: el caso andino del actual del Parque Arqueológico de Pumapungo, en la ciudad de Cuenca, propiedad del Estado Ecuatoriano, y anteriormente de la comunidad Jesuita, quienes construyeron su convento y colegio sobre el centro incaico de Tomebamba; y, el Convento e Iglesia de San Bernardino de Siena en el área patrimonial de Xochimilco en Ciudad de México, edificaciones de igual manera construidas sobre centros ceremoniales de la cultura Azteca, y que continuan dando servicios religiosos catolicos al sector. En ambos casos la Iglesia se posesiono sobre importantes centro urbanos religiosos prehispánicos para construir sus edificaciones dentro del proceso de evangelización, pero que posteriormente estos vestigios fueron descubiertos. En el caso andino se han realizado trabajos de salvaguarda y rescate topográfico, pero en el caso mexicano, son actuales las investigaciones que indican la existencia de estas construcciones prehispánicas, por lo que, dado el arraigamiento cristiano, es incierto el futuro rescate patrimonial no católico.

\section{EL CARÁCTER TURÍSTICO DEL PATRIMONIO CULTURAL URBANO DES CARACTERIZADO POR LA RELIGIÓN}

Parecería ser que estos nuevos usos del espacio religioso, beneficiados en varios aspectos, serían una nueva forma de comercio, que valiéndose de sus condiciones culturales podrían convertirse en centros de atracción turística. En los que, en algunos de los casos, el fin turístico se muestra generalizado, desvirtuando sus naturales nombres y costumbres de carácter religioso. En el caso de España, Delgado Ruiz apunta entre varios, el de Barcelona "Los mercados de Santa Catalina y de la Boquería están donde estaban el monasterio de Jerusalén y el de Santa Catalina" (1997, p.176).

A pesar de ello, con el avanzar del tiempo esta imposición se verá también amenazada por movimientos anticlericales, que según Delgado Ruiz (1997), con una visión modernista alineada a una desterritorialización capitalista, reemplazará sus espacios urbanos y también rurales, por espacios que cumplan con este orden ideológico-cultural en España entre los siglos XIX y XX, así como también en América Latina. De la misma manera, la superposición de edificaciones, monumentos y semejantes de la iglesia católica sobre los elementos y construcciones prehispánicos de carácter religioso, encontró en su momento una forma de sometimiento.

Así, la idea de turismo como forma de reactivación económica, principalmente, tiene sus inicios con el llamado Grand Tour en Europa en la década de 1850 (DELGADO RUIZ, 1997). Iniciativa económica que será posteriormente implementada también en América Hispánica, en donde aún se está identificando el patrimonio cultural y natural. Reconocimiento que genera conflictos, porque la

$\begin{array}{llllll}\text { Caminhos de Geografia } & \text { Uberlândia - MG } & \text { v. 19, n. 68 } & \text { Dez/2018 } & \text { p. 296-306 Página } 303\end{array}$


presencia mestiza e indígena debe a su vez encaminar sus prácticas, con el propósito de obtener también un beneficio económico de esta actividad. "A fin de cuentas la cultura, o más concretamente, los rasgos culturales que caracterizan a cada grupo humano, tienen mucho que ver con las formas en que ese grupo se ha enfrentado a su entorno, a ese ámbito natural construido que se ha ido transformando según los individuos intervenían en él” (PASTOR ALFONSO, 2003, p. 102). Además del hecho que, si bien la cultura prehispánica fue modificada, aun mantiene lazos estrechos con su pasado, del que da cuenta el espacio geográfico y paisaje por el que está rodeada.

Es así que la herencia cultural sobrevenida se convierte en un paisaje turístico con enfoques mercantilistas que encuentra en el valor patrimonial, posibilidades de lucro con una estrategia empresarial de carácter estatal y privada. Siendo uno de los modelos más difundidos, el propuesto por Butler (1980, p. 7), que propone dos ejes en base al: temporal y al numero de turistas, una hipotética evolución de un área turística. Este ciclo evolutivo identifica cinco etapas, la exploración, el envolvimiento, el desarrollo, la consolidación, y el estancamiento, a partir del cual, puede darse una vigorización o un declinar de esta zona turística. Cabe aclara, que no se pretende un análisis desde este aspecto, y el mencionado modelo, mas sí como un medio, para entender que las propuestas de turismo cultural están ligadas a un ciclo productivo que no puede ser ignorado, ya que las consecuencias de éste sobre el patrimonio cultural pueden acabar con el mismo, aceptando el hecho de que muchos otros factores de impacto, de entre los cuales la especulación del suelo urbano, parece tomar la iniciativa, al supera los principios de salvaguarda patrimonial y ecológica, para conseguir lucro de la cultura.

Tomando esta hipotética evolución de Butler, y colocando los dos ejemplos de patrimonio cultural mestizo en América Hispánica en la etapa de la vigorización o el declino, en función de las actividades turísticas llevadas a cabo en éstos, se puede identificar que. Por su parte Pumapungo ha conseguido sobrellevar las amenazas de salvaguarda patrimonial y ecológica, al ser un área a cargo del Ministerio de Cultura del Ecuador. Que lo convirtió en Parque Arqueológico y Museo, impidiendo de alguna manera la intervención de intereses inmobiliarios sobre ésta área caracterizada por una ubicación privilegiada en el Centro Histórico de la ciudad. Se puede incluir como beneficio, que la gestión del espacio patrimonial está controlada por personal capacitado para esta tarea, y que las actividades de turismo no poseen fines de lucro.

Para el caso de Xochimilco, en el área en donde se emplaza el monasterio y la iglesia de San Bernardino de Siena, la realidad es otra, ya que estos terrenos continúan perteneciendo a la Iglesia, y continúan prestando sus respectivos servicios religiosos. El recinto puede ser visitado turísticamente sin ningún control, los espacios carecen de manutención al exterior, y si bien está limitado, anteriormente estaba integrado al paisaje lacustre agrícola característico del sector. Siendo el delicado entorno paisajista, tanto patrimonial como ecológico, que se enfrenta a una constante amenaza de los variados planes y propuestas pensados para recuperar esta área patrimonial, pero que no han llegado a ejecutarse, afortunadamente, ya que no dialogan con la salvaguarda del patrimonio declarado, entre los cuales se menciona la construcción de mega proyectos comerciales, además de la importante expansión urbana, "El impacto de la urbanización no es solo físico: en 2005 solo el $3 \%$ de la población se dedicaba a la agricultura y el $95 \%$ de las chinampas del centro de Xochimilco estaban abandonadas y algunas han sido urbanizadas" (DELGADILLO, 2017, p. 111). Pudiendo así calificarlos de frontales atropellos a los derechos humanos y al sistema lacustre, por lo que actualmente es considerada un área en alerta ambiental, a la que se suman las perdidas patrimoniales, a toda el área de Xochimilco.

En este sentido el patrimonio cultural no garantiza la salvaguarda de un área declarada, peor aún podría minarla al ofrecer una salida económica del usufructo de la misma. Pero este hecho no es nuevo, está intrínsecamente contemplado al tornar en estrategia empresarial la herencia cultural. De acuerdo con Judd, una de las formas empleadas para gestionar el patrimonio ha sido dividirlo, para volverle alcanzable para los turistas, "Los paquetes turísticos desmitificaban los lugares visitados, disgregándolos en partes manejables, cada una de las cuales era portadora de importancia y significado." (PASTOR ALFONSO, 2003, p. 54). Acción a su vez, fracciona la patrimonialidad del lugar y de quienes viven en el, debido a que se convierten en áreas restringidas, al limitar su accesibilidad, en las que el factor económico se muestra como la actual barrera a superar, ya que la de la religión de alguna manera se camufla como aparente aportadora de valor a este patrimonio materializado, sin que ésto signifique la salvaguarda del espacio en cuestión. 


\section{CONSIDERACIONES FINALES}

El patrimonio cultural hispanoamericano desde su origen conlleva una lucha por encontrar su particularidad en medio de una dominación cultural religiosa y económica. De esta manera la religión tomó parte de este proceso, integrándose en función de su protagonismo evangelizador que, se materializaría de variadas maneras sobre la cosmovisión del territorio americano. Hecho que, hoy por hoy, parece ser suplantado por el dogma de un sistema mercantilista, que muestra al turismo como el catalizador para la salvaguarda del patrimonio.

Sin embargo, este 'catalizador', opta por una forma de negociación hacia la especificidad cultural y paisajista de los lugares patrimoniales considerados turísticos en América Latina, en la que la salvaguarda no representa un objetivo a alcanzar. Siendo posiblemente, la marcada diferenciación y tratamiento dados a estas áreas, lo que ha complicado aun más la importancia de reconocer el valor cultural de la herencia originaria americana, para mitigar los impactos al patrimonio cultural material, inmaterial, y su patrimonialidad en las áreas urbanas de estas ciudades.

\section{AGRADECIMIENTOS}

Este trabajo es realizado gracias a la beca de estudio otorgada por la Organización de los Estados Americanos OEA, amparada en el Programa de Alianças para Educação e Capacitação -PAEC-OEAGCUB 2014. Para el programa de Pos Graduación, Doctorado en Geografía 2015-2019, en la Universidade Federal de Uberlândia, Brasil.

\section{REFERENCIAS}

ALCINA, José. Procreación, amor y sexo entre los mexica. Estudios de cultura Náhuatl volumen 21. Universidad Nacional Autónoma de México,1991. p. 59-82.

BANCO CENTRAL. Educación en torno a Pumapungo. Cuenca: Dirección Regional de Cultura de Cuenca, 1997. p.50.

BUTLER, R.W. The concept of a tourist area cycle of evolution: Implications for management of resources. The Canadian Geographer/ Le Géographe canadien, XXIV, 1. 1980. p. 5-12.

CANO VALLADO, José. Las chinampas del Valle de México. Agricultura y sociedad en México: diversidad, enfoques, estudios de caso. México: Universidad Iberoamericana, 1999.

CIEZA DE LEÓN, Pedro. Crónica del Perú El Señorío de los incas. Caracas: Biblioteca Ayacucho, 2005. p.497.

DELGADILLO, Víctor. Conflictos en áreas centrales de conservación patrimonial en la Ciudad de México. Habitar la centralidad urbana. Ciudad de México: Universidad Autónoma Metropolitana, 2017. p. 89-115.

DELGADO RUIZ, Manuel. Anticlericalismo, espacio y poder. La destrucción de los rituales católicos, 1931-1939. Ayer, No. 27, EL ANTICLERICALISMO, 1997. p. 149-180.

ESTRELLA, Eduardo. El pan de América. Etohistoria de los alimentos aborígenes en el Ecuador. $2^{\mathrm{a}}$ Edición. Quito: Ediciones Abya-Yala, 1988. p. 390.

GIBSON, Charles. Los aztecas bajo el dominio español (1519-1810). Cuarta edición en español. México: siglo xxi editores, 1978. p.530.

GISBERT, Teresa; MESA, José de. Arquitectura Andina. Historia y análisis. La Paz: Colección, Arsánz y Vela/Embajada de España en Bolivia, 1985.

INAH. Mediateca. Web. 20 mayo, 2017.

HARDOY, Jorge E. Las formas urbanas europeas durante los siglos XV al XVII y su utilización en América Latina. Urbanización y proceso social en América. Instituto de Estudios peruanos, 1972. p.171-172.

JUDD, Dennis, R. El turismo urbano y la geografía de la ciudad. Revista eure, vol. XXIX, № 87.

Santiago de Chile: septiembre 2003. p. 51-62.

$\begin{array}{llllll}\text { Caminhos de Geografia } & \text { Uberlândia - MG } & \text { v. 19, n. } 68 & \text { Dez/2018 } & \text { p. 296-306 } & \text { Página } 305\end{array}$


MANRÍQUEZ, Viviana, S. El término Ylla y su potencial simbólico en el Tawantinsuyu. Una reflexión acerca de la presencia inca en Caspana (río Loa, desierto de Atacama). Estudios Atacameños:

Arqueología y antropología surandinas. № 18. San Pedro de Atacama: Instituto de Arqueología y Antropología, Universidad Católica del Norte, 1999. p.107-118.

MORALES, Alfredo, J. Nuevos datos sobre capillas abiertas españolas. II Jornadas de Andalucía y América: Andalucía y América en el Siglo XVI. Escuela de Estudios Hispano-Americanos de Sevilla: 1983. p. 453-463.

PASTOR ALFONSO, María José. El patrimonio cultural como opción turística. Horizontes Antropológicos, ano 9, n. 20. Porto Alegre: outubro de 2003. p. 97-115

STEPHAN-OTTO, Erwin. Plan de manejo integral de la zona chinampera. Ciclo de conferencias: "las chinampas y los canales de Xochimilco y Tláhuac" asamblea legislativa del Distrito Federal. Parque Ecológico de Xochimilco, 1998. p. 1-33.

VASCONCELOS, José. La raza cósmica. Tercera edición. Primera edición, 1948. México: Editorial Porrúa, 2005. p.164.

WINDUS, Astrid. The Embodiment of Sin and Virtue. Visual Representations of a Religious Concept in a Colonial Andean Contact Zone. Cultural Encounters and the Discourses of Scholarship. Volume 3. Münster: Deutsche Nationalbibliothek, 2011. p. 93-114.

Recebido em: 21/12/2017

Aceito para publicação em: 05/11/2018 